This is a pre-copyedited, author-produced PDF of an accepted version of; Okuwaki, R., Fan, W., Yamada, M., Osawa, H., \& Wright, T. J., Identifying landslides from continuous seismic surface waves: a case study of multiple small-scale landslides triggered by Typhoon Talas, 2011, Geophys. J. Int., https://doi .org/10.1093/gji/ggab129.

\title{
Identifying landslides from continuous seismic surface waves: a case study of multiple small-scale landslides triggered by Typhoon Talas, 2011
}

\author{
Ryo Okuwaki ${ }^{1,2}$, Wenyuan Fan ${ }^{3}$, Masumi Yamada ${ }^{4}$, Hikaru Osawa $^{1} \&$ Tim J. Wright $^{2}$ \\ ${ }^{1}$ Mountain Science Center, Faculty of Life and Environmental Sciences, University of Tsukuba, Tsukuba, Ibaraki 305-8572, Japan \\ E-mail: rokuwaki@geol.tsukuba.ac.jp \\ ${ }^{2}$ COMET, School of Earth and Environment, University of Leeds, Leeds LS2 9JT, UK \\ 3 Scripps Institution of Oceanography, UC San Diego, La Jolla, California 92093, USA \\ ${ }^{4}$ Disaster Prevention Research Institute, Kyoto University, Uji, Kyoto 611-0011, Japan
}

\section{SUMMARY}

Landslides can cause devastating damage. In particular, heavy rainfall-triggered landslides pose a chain of natural hazards. However, such events are often difficult to detect, leaving the physical processes poorly understood. Here we apply a novel surface-wave detector to detect and locate landslides during the transit of Typhoon Talas 2011. We identify multiple landslides triggered by Typhoon Talas, including a landslide in the Tenryu Ward, Shizuoka prefecture, Japan, $\sim 400 \mathrm{~km}$ east from the typhoon track. The Tenryu landslide displaced a total volume of $1.2-1.5 \times 10^{6} \mathrm{~m}^{3}$. The landslide is much smaller than those detected by using globally recorded surface waves, yet the event generated coherent seismic signals propagating up to $3000 \mathrm{~km}$ away. Our observations show that attributes of small and large landslides may follow the same empirical scaling relationships, indicating possible invariant failure mechanisms. Our results also suggest an alerting technology to detect and locate landslides with a sparse seismic network.

Key words: Time-series analysis - Seismic noise - Surface waves and free oscillations Wave propagation - Tectonics and landscape evolution. 


\section{INTRODUCTION}

Deep-seated catastrophic landslides can displace mass over a large range of volumes rapidly and can cause significant hazards to mountain communities and infrastructure (Spiker and Gori 2003; Hewitt et al. 2008; Hibert et al. 2011; Ekström and Stark 2013; Chigira et al. 2013). Mitigations of such disastrous events rely on robust monitoring of landslide failure processes, yet most observations of landslide dynamics remain retrodictive. Broadband seismic observations can help detecting and locating these events even when landslides are distant from the seismic networks (Ekström and Stark 2013; Fan et al. 2020).

Landslides can generate broadband seismic signals (Kanamori and Given 1982; Kawakatsu 1989; Brodsky et al. 2003; Allstadt 2013; Hibert et al. 2015). Short-periods (<1 s) (Hibert et al. 2011; Yamada et al. 2012; Doi and Maeda 2020) and intermediate- to long-periods (20 to 150 s) (Moretti et al. 2012; Ekström and Stark 2013; Allstadt 2013; Li et al. 2019; Zhang et al. 2019) seismic signals are commonly used for detecting landslides and studying landslide dynamics. For example, short-period signals have proven efficient for detecting and evaluating landslides (Dammeier et al. 2016; Manconi et al. 2016; Dietze et al. 2017; Chao et al. 2017; Fuchs et al. 2018). However, such operations are often limited to local or regional distances due to seismic attenuation. The intermediate- to long-period (35 to $150 \mathrm{~s}$ ) seismic surface waves are the primary means to detect and locate distant landslides (Ekström 2006; Ekström and Stark 2013). For example, Rayleigh waves have proven effective for detecting teleseismic landslides (Ekström 2006; Lin et al. 2010). These landslides can displace $\geq 2 \times 10^{10} \mathrm{~kg}$ rocks and generate surface waves with amplitudes equivalent to those of $M \geq 4.6$ earthquakes (Ekström 2006; Ekström and Stark 2013). In contrast, smaller size landslides are infrequently reported from surface wave detectors, leaving their occurrence poorly understood. Recently, automatic classifiers show promises in detecting small landslides from continuous regional seismic records (e.g. Dammeier et al. 2016; Hibert et al. 2017; Provost et al. 2017). However, such algorithms have not been applied to systematically locate landslides due to the limited seismic network coverage (Hibert et al. 2019).

The 2011 Typhoon Talas brought precipitation exceeding $2000 \mathrm{~mm}$ and caused 50+ landslides adjacent to the typhoon track in Nara, Wakayama and Mie prefectures in western Japan (Yamada et al. 2012; Chigira et al. 2013) (Fig. 1). Among them, 18 landslides were detected and located by using short-period ( 0.25 to $1 \mathrm{~s}$ ) seismic records near the landslide sources (Yamada et al. 2012). However, due to seismic attenuation of these waves, such procedure is inadequate to detect landslides that were away from the Typhoon track. Intriguingly, the precipitation in Shizuoka prefecture is over $1000 \mathrm{~mm}$, which is $\sim 400 \mathrm{~km}$ away from 


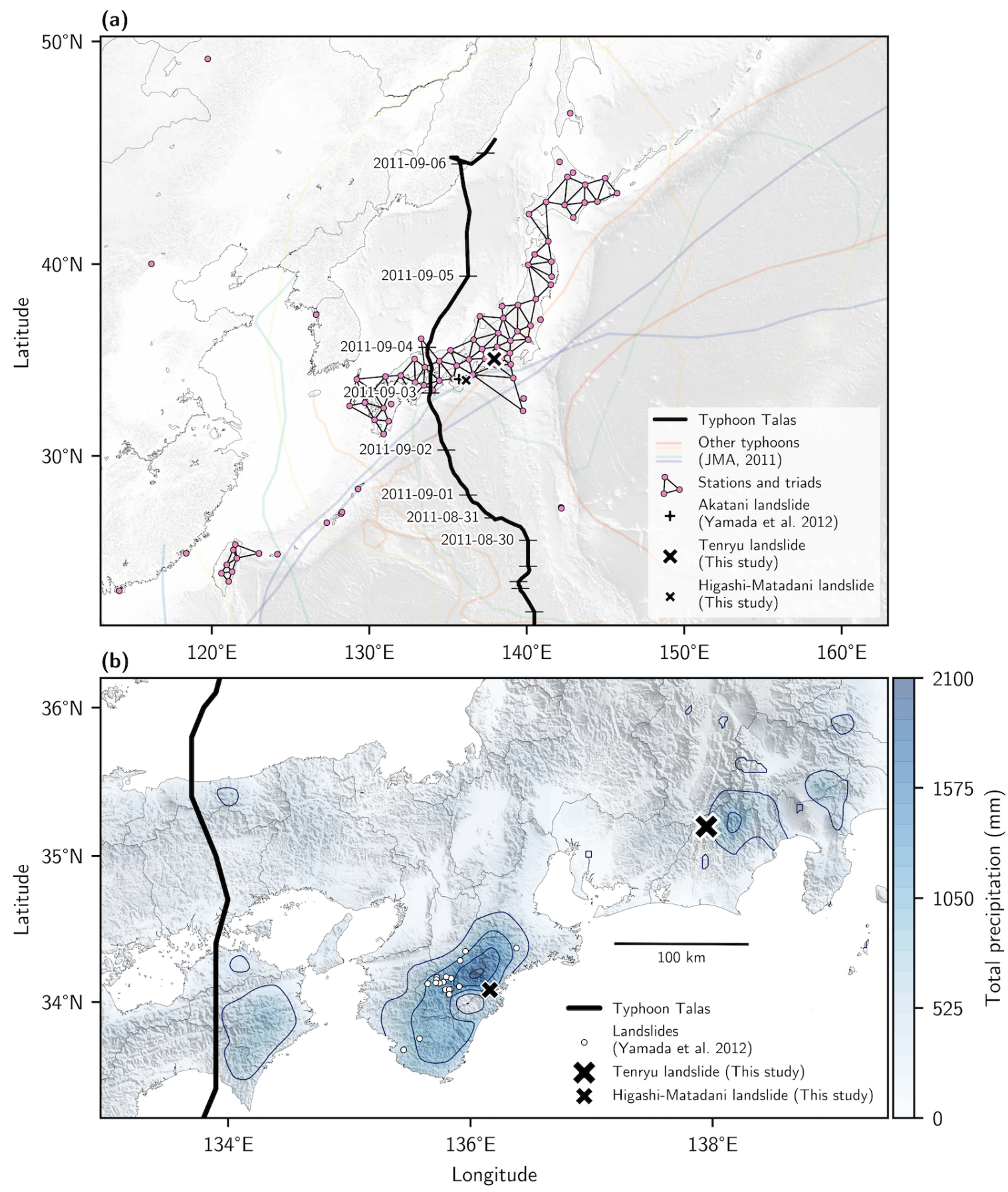

Figure 1. Overview of the study area. (a) Map shows the available seismic stations during the study period, the track of Typhoon Talas, and the landslide locations. Background topography/bathymetry are from the GEBCO 2019 Grid (GEBCO Bathymetric Compilation Group 2019 2019). (b) Background colour is the total precipitation during August 30, 2011 to September 6, 2011 observed at the Automated Meteorological Data Acquisition System (AMeDAS) stations. The blue contour denotes every $500 \mathrm{~mm}$ total precipitation. The grey lines denote the administrative boundaries. 
the typhoon track (Fig. 1b). However, no landslides were reported in this region by previous seismic studies (e.g. Yamada et al. 2012).

Here we apply a surface-wave detector that is based on the AELUMA method (Automated Event Location Using a Mesh of Arrays) (de Groot-Hedlin and Hedlin 2015; Fan et al. 2018) to investigate landslide activities across Japan during the transit of Typhoon Talas. This method has been applied to the USArray with over 400 stations and located various unconventional seismic sources (Fan et al. 2018, 2019, 2020). In this study, we identify three new landslides, including one in Tenryu, Shizuoka prefecture, which is $400 \mathrm{~km}$ away from the track of Typhoon Talas. The landslide generates coherent surface wavefields that are recorded by stations across Japan and Taiwan but only displace a total volume of $1.2-1.5 \times 10^{6} \mathrm{~m}^{3}$ (Kanto Regional Forest Office Japan 2012; Seo et al. 2012; Yumoto and Takashima 2013). The results show promises of future near-real-time monitoring of landslide activities in Japan.

\section{DATA}

We use continuous seismic data from 103 stations of the National Research Institute for Earth Science and Disaster Resilience F-net (NIED 2019) and the Broadband Array in Taiwan for Seismology TW (IES 1996) networks shown in Figure 1a. We download the verticalcomponent long-period (1-s-sampled LHZ) records of September 3 to 4, 2011, during Typhoon Talas' transit in Japan (Fig. 1a) (Yamada et al. 2012). We then remove the instrumental response to utilise data from different instruments. The records are bandpass filtered at 20 to $50 \mathrm{~s}$ with a 4 th-order non-causal Butterworth filter.

\section{METHOD}

\subsection{Detecting and locating seismic sources using seismic surface waves}

We apply the AELUMA-based surface-wave detector to detect and locate seismic events. Following de Groot-Hedlin and Hedlin (2015), we first divide the 103 stations into nonoverlapping 68 triangular subarrays (triads), and remove triads with internal angles beyond the range of $30^{\circ}$ to $120^{\circ}$ (Fig. 1a) (Lee and Schachter 1980; Thompson and Shure 2016). Second, we apply tau-p beamforming analysis for each triad, and measure relative travel times between station pairs of coherent signals to solve for a centroid arrival time and a propagation direction (Fig. S1). Third, the detections are aggregated into non-overlapping clusters. We then invert the seismic source locations with the clusters by grid-searching possible source locations (Fan et al. 2018). To neutralise off-great-circle path propagation ef- 
fects, we also apply empirical calibrations from measurements of earthquakes in the Global Centroid Moment Tensor (GCMT) project (Dziewonski et al. 1981; Ekström et al. 2012) and landslides reported in a previous study (Yamada et al. 2012). After obtaining the source locations, we finally perform a quality control step to discard sources detected by less than 10 triads. These empirical parameters are different than those applied to the USArray (e.g. Fan et al. 2018), but comparable parameters were examined in de Groot-Hedlin and Hedlin (2018) and proven effective. Details of the algorithm are described in Fan et al. (2018) and de Groot-Hedlin and Hedlin (2015).

\subsection{Centroid-single force modelling}

To investigate the source mechanisms of the newly identified seismic sources (e.g. seismic event E1, Fig. 2, Table 1), we perform the seismic waveform inversion to model the source as centroid-single forces (CSF) (Kawakatsu 1989; Tsai and Ekström 2007; Ekström and Stark 2013). As discussed later, our newly identified seismic sources (e.g. seismic event E1, Fig. 2, Table 1) are likely landslides, which show clear seismic surface waves in a narrow intermediate period band (20 to $50 \mathrm{~s}$ ) but do not show clear $P$ - or $S$-arrivals (Figs. 3, 4, and S5). We adopt a conventional time-domain method (e.g. Fan et al. 2020) to obtain a CSF model of the seismic source. The method assumes the force functions at three directions are equal-time length symmetric boxcar functions, representing a constant initial acceleration and an equalduration, equal-amplitude arresting deceleration. For a candidate CSF model, we calculate the associated synthetic seismograms by convolving the model with Green's functions, and evaluate the model in the time domain for an average minimum $\ell_{2}$ waveform-misfit (Fan et al. 2020). We construct CSF models to explain both the Rayleigh and Love waves (20 to $50 \mathrm{~s}$ ) at stations within $150 \mathrm{~km}$ (e.g. Fig. 5a). In practice, we grid-search the source duration and the three centroid force amplitudes in a $4 \mathrm{D}$ model-space with ranges from $-2 \times 10^{10}$ to $2 \times 10^{10} \mathrm{~N}$ for the up-down, north-south and east-west components, and from 10 to $50 \mathrm{~s}$ for the duration. The search steps are $0.05 \times 10^{10} \mathrm{~N}$ for up-down and east-west components and $0.005 \times 10^{10} \mathrm{~N}$ for a north-south component. We test durations of 10, 20, 24, 30, 34, 40, and $50 \mathrm{~s}$. We compute nine-components of force-source Green's functions for each sourcestation pair at the three directions using the Instaseis method (van Driel et al. 2015). The Instaseis method uses a pre-computed Green's function database, which is calculated by the axisymmetric spectral-element code AxiSEM with the anisotropic version of the PREM model up to $5 \mathrm{~s}$ (Nissen-Meyer et al. 2014; Dziewonski and Anderson 1981). This allows efficient computation of broadband synthetic seismograms and a relative complete search of 
the model space. This Green's function database can be directly obtained from IRIS DMC Syngine (Krischer et al. 2017). The regional geological structures are complex and can have strong velocity effects. Such effects dominantly show as arrival time anomalies. We correct the crust-heterogeneity effects by cross-correlating the observed and synthetic waveforms and aligning them before computing the waveform misfit. Both the observed and synthetic waveforms are resampled at $1 \mathrm{~s}$ and filtered at 20 to $50 \mathrm{~s}$ with a 4th-order Butterworth bandpass filter before the waveform misfit calculation. Even though source kinematics can be rather complex (Yamada et al. 2013, 2018; Moretti et al. 2012, 2020), the simple boxcar landslide models are representative of the ground loading and unloading processes for the sliding processes because of us focusing on the intermediate-period (20 to $50 \mathrm{~s}$ ) surface waves. As shown in the sections below, the models prove sufficient in explaining the seismic observations well (Fig. 5c).

\section{RESULTS}

\subsection{Overview of the detected seismic events}

We initially located 25 seismic events from September 3 to 4, 2011 (Table S1). We further screen the events by visually inspecting the waveform records aligned with the source epicentres, and events that generate coherent wave trains are kept for further analysis. This quality control step removes 9 events (e.g. Fig. S2), and leaves 16 candidate events for further analysis (e.g. Fig. 2a). Thirteen of the candidate events are earthquakes in standard earthquake catalogs (Dziewonski et al. 1981; Ekström et al. 2012; Japan Meteorological Agency 2011; U.S. Geological Survey Earthquake Hazards Program 2017) and two sources were landslides reported in Yamada et al. (2012) (Table 1). We find one new unknown seismic event (E1) based on the initial set of parameters (Fig. 2b). As we detail in the later sections, we also observe weaker coherent phases following this new unknown source (Figs. 2a and S4a). After re-examining the propagation direction and centroid time measurements, we identify two more events (E2 and E3) related to those signals, which are also absent in the standard earthquake or landslide catalogs (Dziewonski et al. 1981; Ekström et al. 2012; Japan Meteorological Agency 2011; U.S. Geological Survey Earthquake Hazards Program 2017; Yamada et al. 2012). Thus in total, we identify three new seismic events (Table 1). 

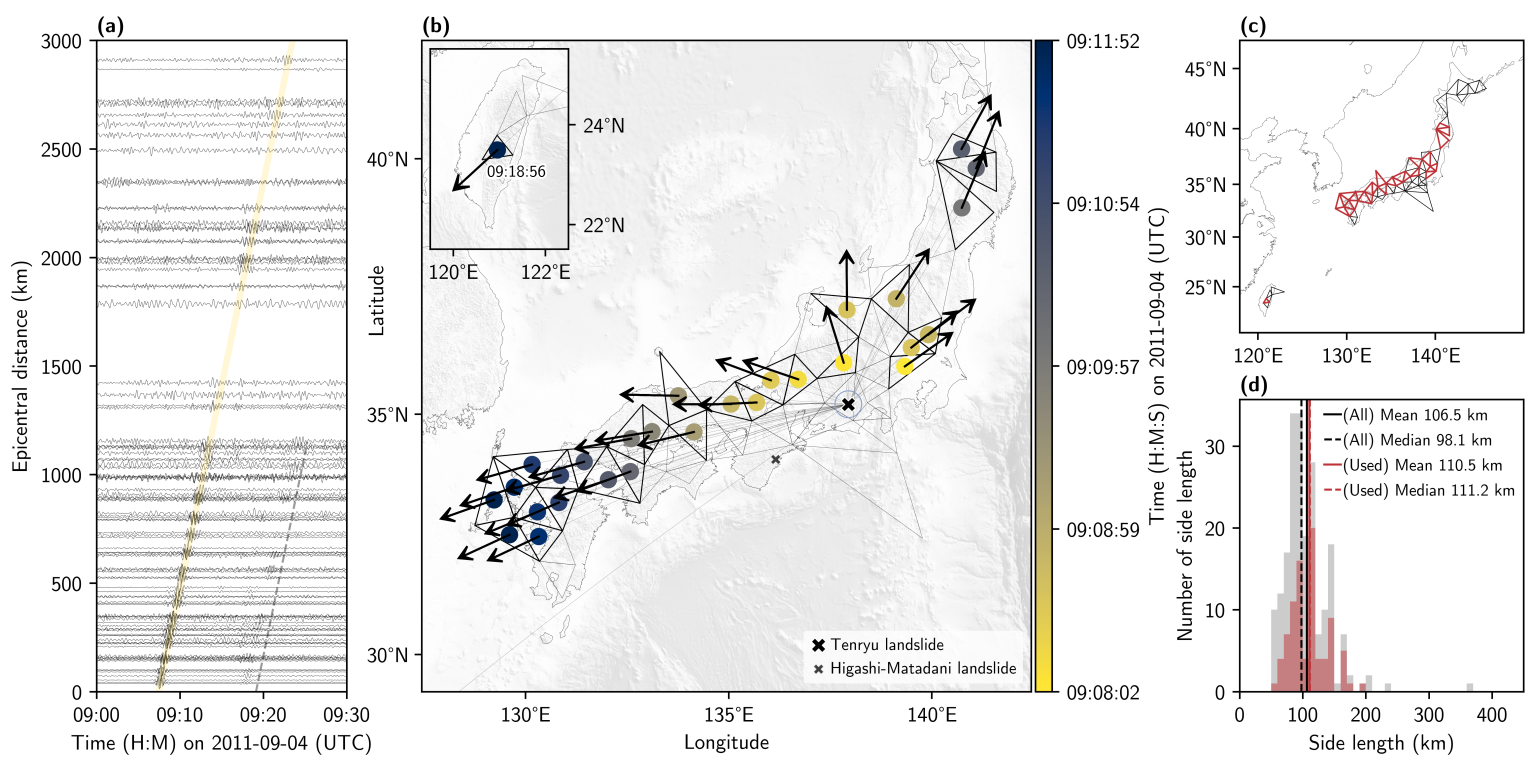

Figure 2. Detection and location of the Tenryu landslide. (a) Self-normalised bandpass-filtered (20 to $50 \mathrm{~s}$ ) waveforms aligned by the epicentre of the Tenryu landslide (E1). The yellow line shows the reference wavefront travelling at a phase velocity of $3.11 \mathrm{~km} / \mathrm{s}$. The dashed line indicates wavetrains travelled from the Higashi-Matadani landslide (E2). (b) The thick and thin triangles are the triad subarrays. The arrow is the observed arrival angle. The colour for each dot represents the observed arrival time. The thin line between the epicentre and the centroid of each triad is the great circle path. The blue ellipse denotes the estimated location uncertainty. Inset is the triad measurement in Taiwan for the Tenryu landslide. (c) Black triangles are the triads available on September 4, 2011. Red triangles are the triads used for detection of the Tenryu landslide (E1). (d) Histogram of the side length of the triads every $10 \mathrm{~km}$ bin.

\subsection{Major landslide E1}

Seismic event E1 occurred on September 4, 2011, 09:07:28 (UTC) in Tenryu Ward, Shizuoka prefecture, Japan $\left(35.1992^{\circ} \mathrm{N}, 137.9479^{\circ} \mathrm{E}\right.$, Fig. $\left.2 \mathrm{~b}\right)$. The waveform record-section of E1 shows a coherent wavefield propagating up to $3000 \mathrm{~km}$ with an estimated phase velocity of $3.11 \mathrm{~km} / \mathrm{s}$ (Fig. 2a). The E1 location is resolved from measurements of 29 triads, including one in Taiwan (2000 km away from the epicentre) (Fig. 2b). The location uncertainty of E1 is $\sim 30 \mathrm{~km}$ (Fig. 2b), which is about one grid separation ( $30 \mathrm{~km}$ ) (Fan et al. 2018). The surface-wave magnitude $\left(M_{\mathrm{SW}}\right)$ (Ekström 2006) of the event is 4.3. Our preferred CSF model of the E1 event has a misfit reduction of $72 \%$ with peak force amplitudes of $0.55 \times 10^{10} \mathrm{~N}, 0.055 \times 10^{10} \mathrm{~N}$, and $0.6 \times 10^{10} \mathrm{~N}$ for the up-down, north-south, and east-west components, respectively (Fig. $5 b)$. The preferred model suggests a source duration of $20 \mathrm{~s}$ and the sharp increase of the 
Table 1. List of landslides identified by this study

\begin{tabular}{cccc}
\hline Landslide name & Time (UTC) & Location & Reference \\
\hline Tenryu (E1) & $2011-09-0409: 07: 28$ & $35.1992^{\circ} \mathrm{N}, 137.9479^{\circ} \mathrm{E}$ & Newly identified by this study \\
Higashi-Matadani (E2) & $2011-09-0409: 16: 58$ & $34.0823^{\circ} \mathrm{N}, 136.1602^{\circ} \mathrm{E}$ & Newly identified by this study \\
pre Higashi-Matadani (E3) & $2011-09-0409: 16: 55 ?$ & $34.0823^{\circ} \mathrm{N}$ ?, 136.1602 ${ }^{\circ} \mathrm{E} ?$ & Newly identified by this study \\
Ohto-Shimizu & $2011-09-0322: 06: 38$ & $34.0447^{\circ} \mathrm{N}, 135.2156^{\circ} \mathrm{E}$ & This study and Yamada et al. (2012) \\
Akatani & $2011-09-0407: 22: 11$ & $34.1557^{\circ} \mathrm{N}, 135.5472^{\circ} \mathrm{E}$ & This study and Yamada et al (2012) \\
\hline
\end{tabular}

data misfit for models of longer durations suggests that the E1 event evolved rapidly (Table 2).

\subsection{Minor landslide E2 and E3}

From the record section in Fig. 2a, we observe a weaker coherent phase $\sim 10$ min after the E1 event. We re-examine the propagation direction and centroid time measurements and locate another event, E2, with only 7 triads. Seismic event E2 is located near Higashi-Matadani in Mie prefecture $\left(34.0823^{\circ} \mathrm{N}, 136.1602^{\circ} \mathrm{E}\right)$, occurring on 09:16:58 (UTC), September 4, 2011 (Fig. S4b) with a location uncertainty of $\sim 30 \mathrm{~km}$. This event is adjacent to the Ohtaki landslide identified in Yamada et al. (2012) but occurred one hour later. There was a Japan Meteorological Agency (JMA) magnitude $\left(M_{\mathrm{JMA}}\right) 1.7$ earthquake in the area, but the near-field short-period records show that E2 was not the $M_{\mathrm{JMA}} 1.7$ earthquake (Figs. S4b and S5). Therefore, E2 was likely a new landslide (e.g. Yamada et al. 2012). We investigate the E2 event with a similar CSF modelling procedure and find that the event can be well explained as centroid single forces (Fig. S6). The estimated duration is $24 \mathrm{~s}$ and the maximum centroid force is $0.34 \times 10^{10} \mathrm{~N}$. Furthermore, we identify a third coherent phase $\sim 3.5 \mathrm{~min}$ before the signals associated with the E2 event (Figs. S3 and S4a). The amplitudes of these signals are about $50 \%$ of those of the E2 event and the signals are about 30 -seconds long. Our surface wave detector cannot locate this seismic event (E3) due to the poor signal-to-noise ratios of records at further away stations. However, this event is likely close to the E2 event because the near-field stations at different azimuths recorded almost equal-separation times between the phases of E2 and E3 (Fig. S3). Although the signals from E3 are less clear in short-period records (Fig. S5), leaving their physical origins ambiguous, they are unlikely regular earthquakes due to a lack of body wave phases. 


\section{DISCUSSIONS}

\subsection{Source characteristics of E1, E2, and E3}

The seismic events detected in this study (E1, E2, and E3) are unlikely typical earthquakes. The seismic sources generated signals that are distinctly different from those of regular earthquakes. For regular earthquakes, e.g., a moment magnitude $\left(M_{\mathrm{W}}\right) 5.1$ earthquake near E1 (with the source duration $\sim 1 \mathrm{~s}$ ), seismic waveforms have clear $P$ - and $S$-wave arrivals, and both short-period ground motions can be identified up to $300 \mathrm{~km}$ away (Fig. 3c). However, we do not observe clear $P$ - and $S$-waves from the E1 at a similar distance range (Fig. 3b). The lack of clear short-period body waves makes it difficult to locate these sources with standard techniques. In contrast, we observe clear and coherent intermediate-period (20 to $50 \mathrm{~s}$ ) surface waves at stations up to $3000 \mathrm{~km}$ (Fig. 2a). Although focusing and defocusing effects due to lateral structural heterogeneity can regulate surface-wave amplitudes in complex ways (e.g. Dalton and Ekström 2006), the lack of short-period body waves and the clear intermediate-period surface waves (Figs. 3 and 4 ) collectively suggest these abnormal seismic radiations are not from typical earthquakes.

Seismic event E1 in Tenryu Ward, Shizuoka city is likely a landslide that was identified by the local forest office in Shizuoka prefecture. This landslide was reported 3 days after our resolved event time and is within $5 \mathrm{~km}$ of our detected seismic source location (Fig. $5 e)$. The landslide was further confirmed by the aerial photos from the Geospatial Information Authority of Japan (Geospatial Information Authority of Japan 2011) and can be clearly identified in the optical satellite imageries (Fig. 6). The field survey used a Laser Profiler to construct a digital elevation model (DEM). By differencing the DEMs before and after the landslide, the elevation changes show that the mass slid 200 to $500 \mathrm{~m}$ along the slope from east to west with a width of $\sim 300 \mathrm{~m}$ (Fig. 5e). The DEM model suggests that the Tenryu landslide displaced a total volume of $1.2-1.5 \times 10^{6} \mathrm{~m}^{3}$, covering a region of $\sim 9.0 \times 10^{4} \mathrm{~m}^{2}$ with a maximum thickness of $\sim 50 \mathrm{~m}$ (Kanto Regional Forest Office Japan 2012; Seo et al. 2012; Yumoto and Takashima 2013). Assuming an average density of $2.6 \times 10^{3} \mathrm{~kg} / \mathrm{m}^{3}$, the landslide might have displaced a total mass of $3.1-3.9 \times 10^{9} \mathrm{~kg}$. To further evaluate the landslide dynamics, we compare the Rayleigh- to Love-wave amplitude ratios of the observed waveforms and the predicted ratio from our preferred CSF model (Fig. 7). The observations show an asymmetric radiation pattern of Rayleigh and Love waves, representing the sliding directivity from east to west, and the model-predicted pattern agrees well with the observations. 

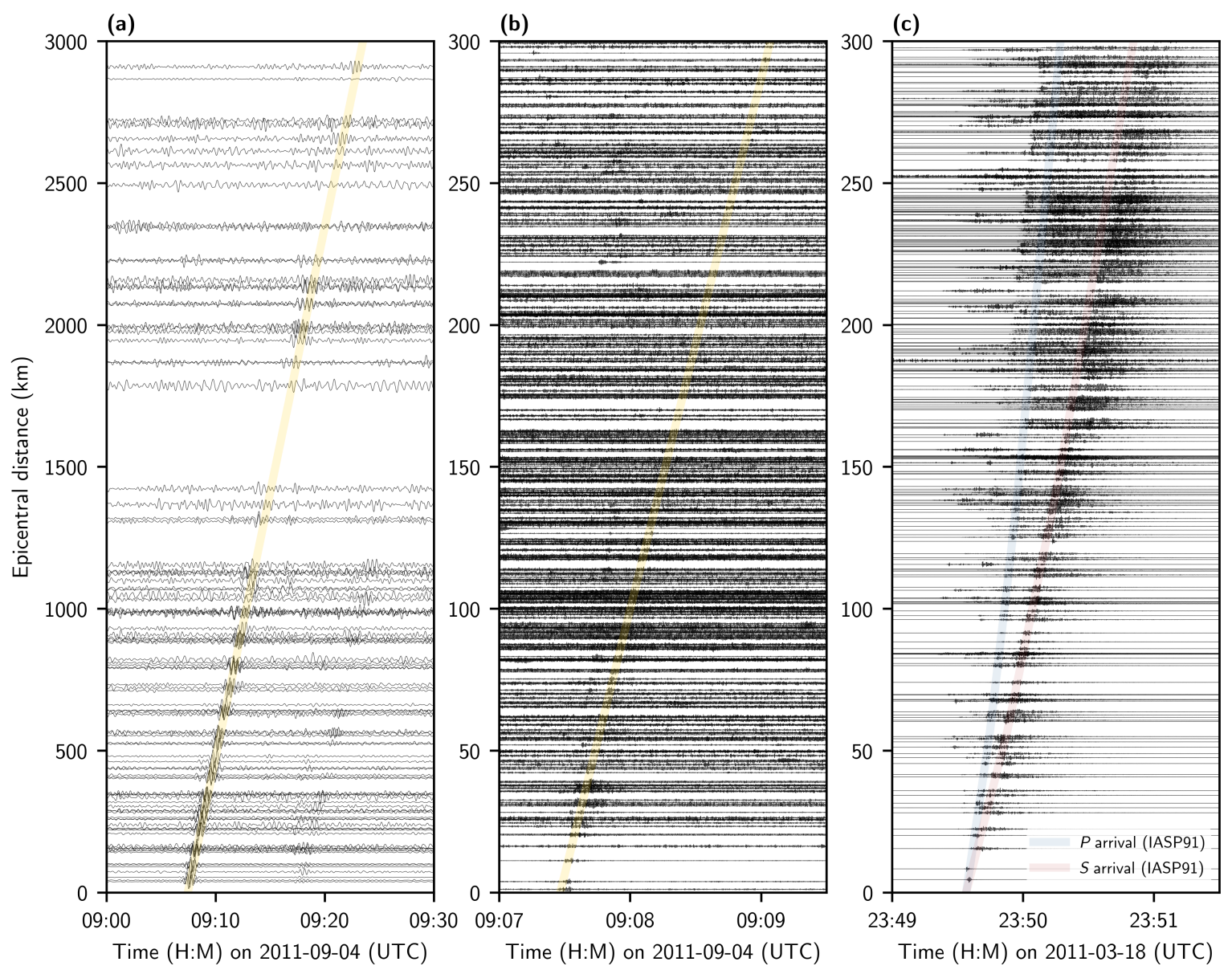

Figure 3. Waveform comparison between intermediate- and short-period data. (a) Self-normalised bandpass filtered (20 to $50 \mathrm{~s}$ ) F-net waveforms aligned by the epicentre of the Tenryu landslide (E1). The yellow line shows the reference wavefront travelling at the phase velocity of $3.11 \mathrm{~km} / \mathrm{s}$. (b) Selfnormalised bandpass filtered ( 0.125 to $0.5 \mathrm{~s}$ ) Hi-net waveforms aligned by the epicentre of the Tenryu landslide (E1). The instrumental response of the Hi-net data was corrected. The yellow line shows the reference wavefront travelling at the phase velocity of $3.11 \mathrm{~km} / \mathrm{s}$. (c) Self-normalised bandpass filtered ( 0.125 to $0.5 \mathrm{~s}$ ) Hi-net waveforms aligned by the epicentre of the $M_{\mathrm{W}} 5.1$ earthquake determined by the GCMT project at $36.730^{\circ} \mathrm{N}, 140.530^{\circ} \mathrm{E}$ on $2011-03-18$ 23:49:34 (UTC). Blue and red lines are the predicted $P$ - and $S$-wave arrivals (IASP91 model; Kennett and Engdahl 1991). 

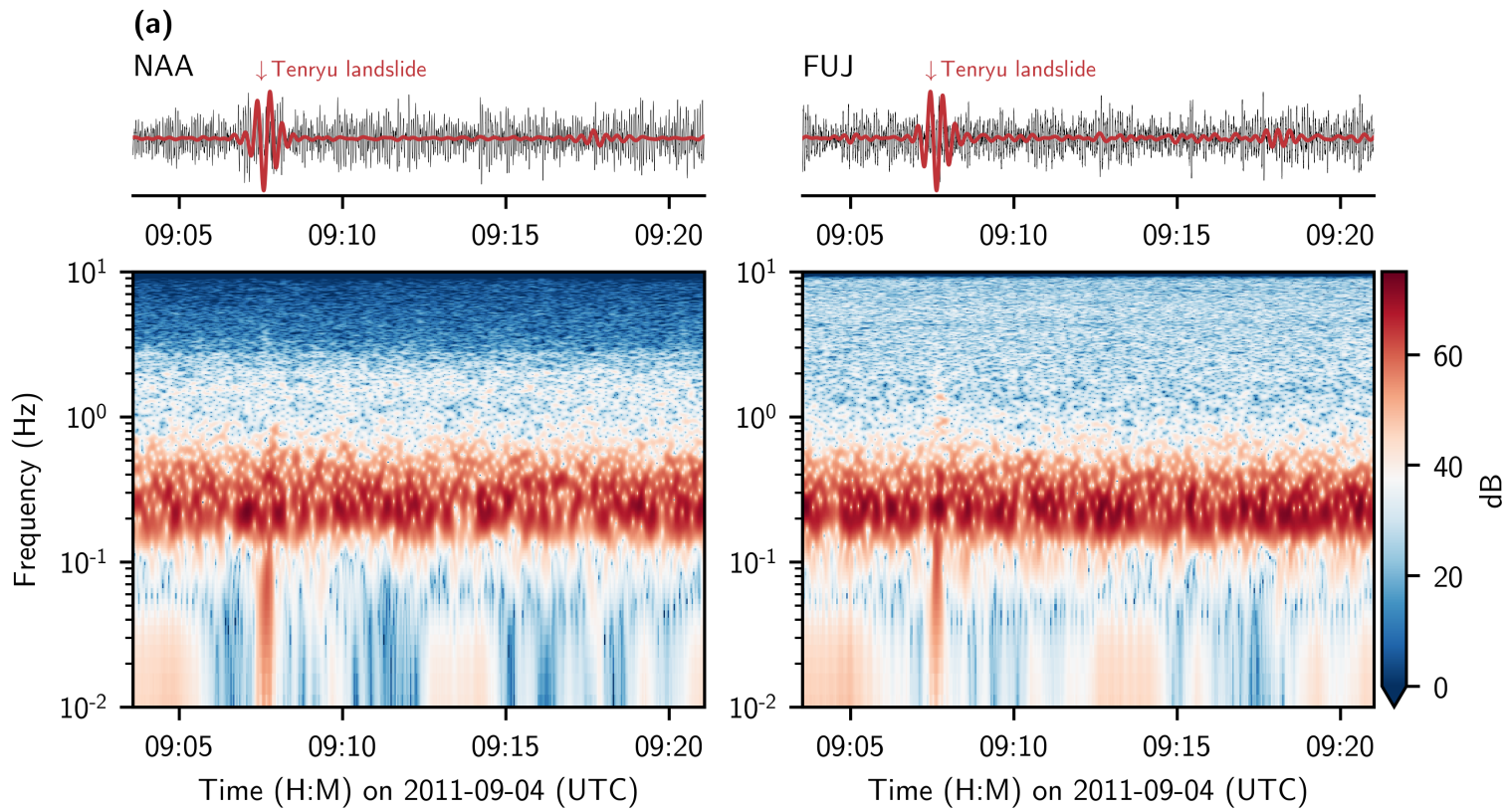

(b)
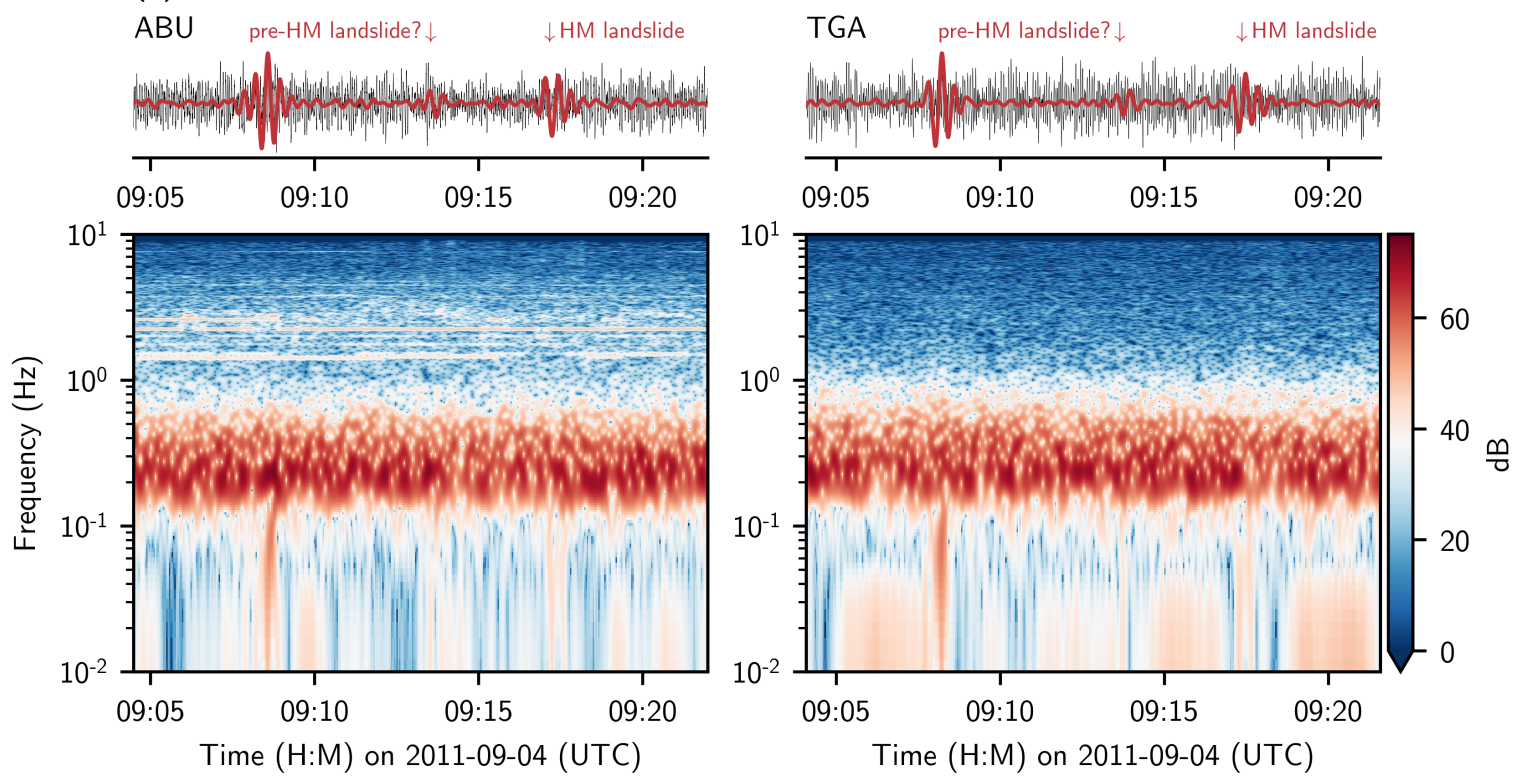

Figure 4. Spectrograms of the near-field broadband F-net records near (a) the Tenryu (E1) and (b) the Higashi-Matadani (HM, E2) landslides. Upper section of each panel shows the self-normalised filtered waveforms applying the 4th order Butterworth high-pass (100 s; black) and bandpass (20 to $50 \mathrm{~s}$; red) filters. Bottom section is the spectrogram. The station code is denoted on the left-top of each panel. The station location is shown in Figs. 5a and S6a. 


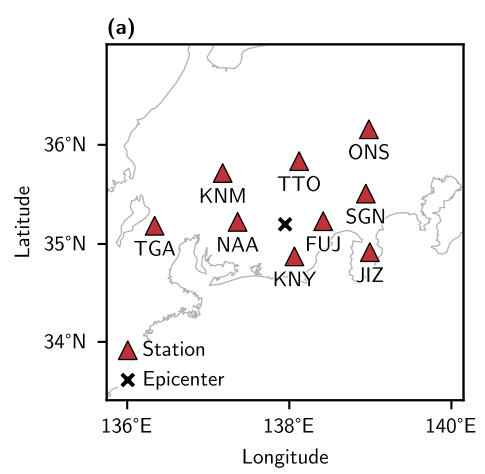

(c)

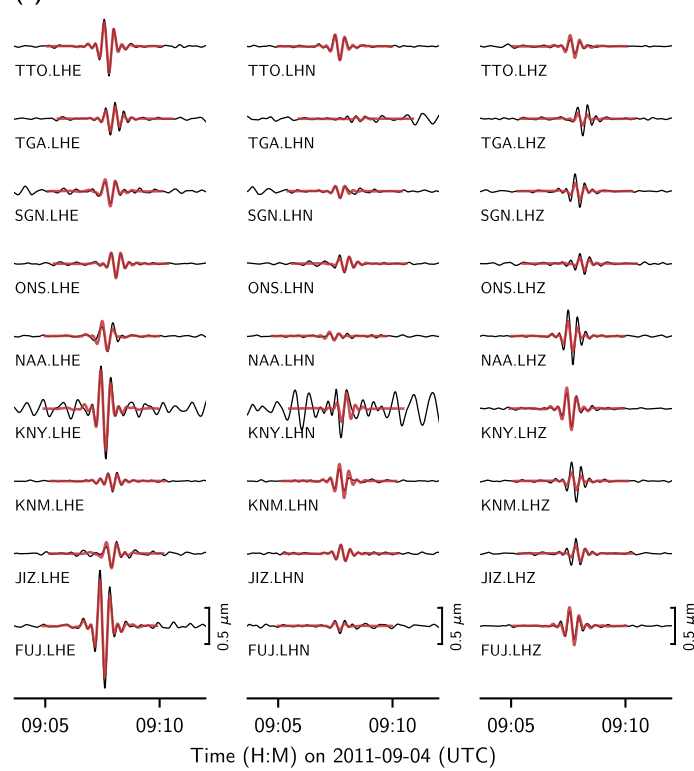

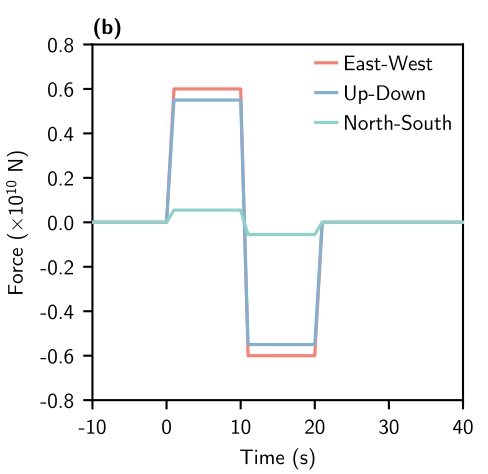
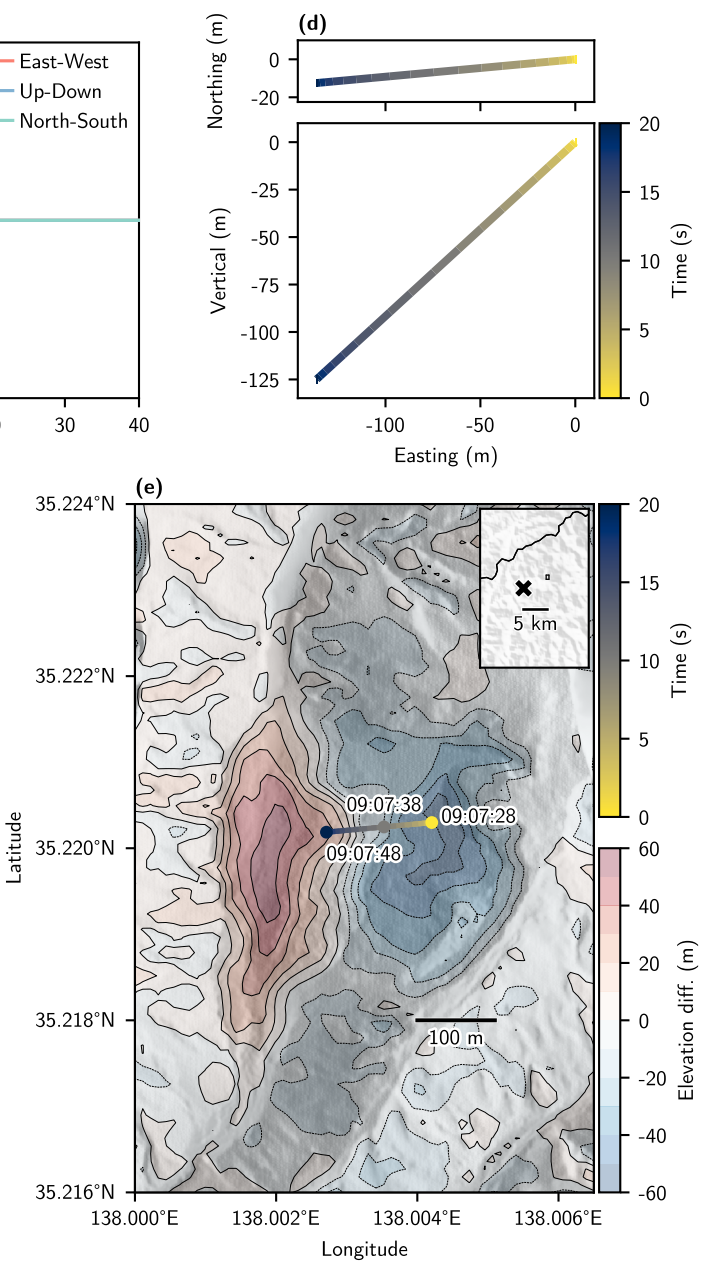

Figure 5. Summary of the centroid single force (CSF) modelling and the digital elevation models (DEMs) of the Tenryu landslide (E1). (a) Distribution of the stations used for the CSF modelling. (b) The inverted three-component force-time function. (c) Black and red lines are the observed and synthetic waveforms, which are bandpass filtered at 20 to $50 \mathrm{~s}$. Station codes and channels are listed on each column. (d) East-North and East-Vertical trajectories (displacements) of the centre of mass. Colour represents the time. (e) Coloured contour denotes the differentiation of DEMs before and after the landslide. Coloured line is the trajectory of the centre of mass, along with the time on September 4, 2011 (UTC). The inset is the regional map. The small rectangle is the area of Fig. 5e. The black line denotes the administrative boundary. 
Table 2. Parameters of the CSF models for the Tenryu landslide (E1)

\begin{tabular}{cccccc}
\hline $\begin{array}{c}\text { Duration } \\
(\mathrm{s})\end{array}$ & Minimum misfit & $\begin{array}{c}F_{\max } \\
\left(\times 10^{10} \mathrm{~N}\right)\end{array}$ & $\begin{array}{c}F_{\text {Up-Down }} \\
\left(\times 10^{10} \mathrm{~N}\right)\end{array}$ & $\begin{array}{c}F_{\text {North-South }} \\
\left(\times 10^{10} \mathrm{~N}\right)\end{array}$ & $\begin{array}{c}F_{\text {East-West }} \\
\left(\times 10^{10} \mathrm{~N}\right)\end{array}$ \\
\hline 10 & 0.300 & 2.02 & 1.35 & 0.145 & 1.50 \\
20 & 0.282 & 0.82 & 0.55 & 0.055 & 0.60 \\
24 & 0.288 & 0.67 & 0.45 & 0.040 & 0.50 \\
30 & 0.353 & 0.67 & 0.45 & 0.035 & 0.50 \\
34 & 0.439 & 0.64 & 0.40 & 0.040 & 0.50 \\
40 & 0.610 & 0.64 & 0.40 & -0.060 & 0.50 \\
50 & 0.738 & 0.65 & 0.40 & 0.080 & 0.50 \\
\hline
\end{tabular}

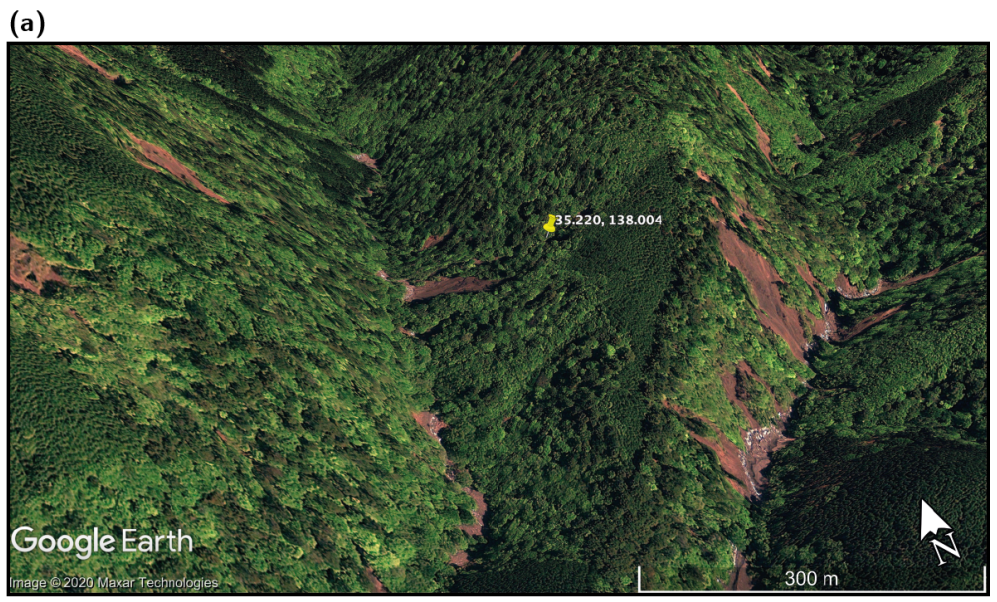

(b)

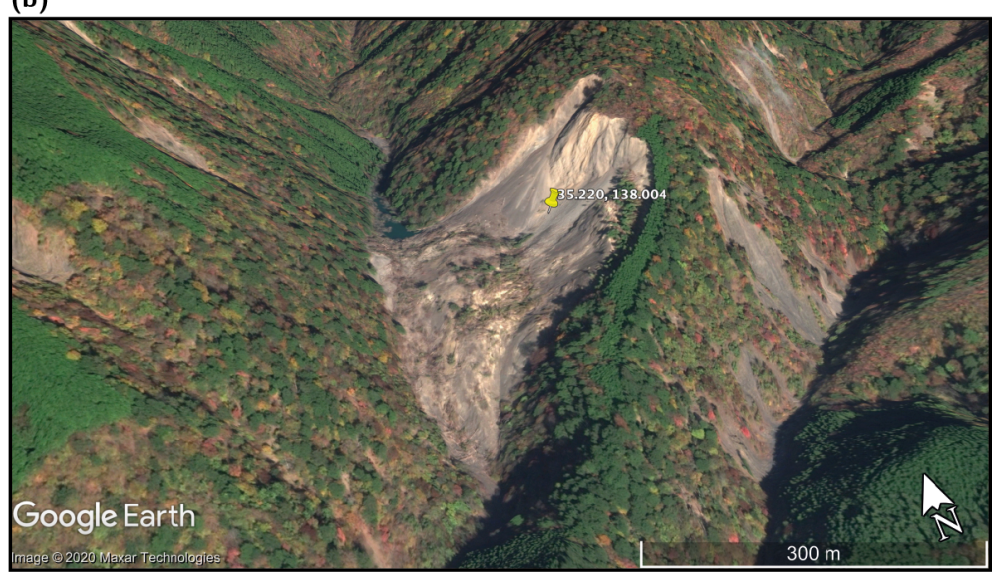

Figure 6. Google Earth ${ }^{\mathrm{TM}}$ imagery (a) before (May 13, 2010) and (b) after (November 15, 2011) the Tenryu landslide (E1), provided by Maxar Technologies. 
14 Okuwaki, R., Fan, W., Yamada, M., Osawa, H. \& Wright, T.J.

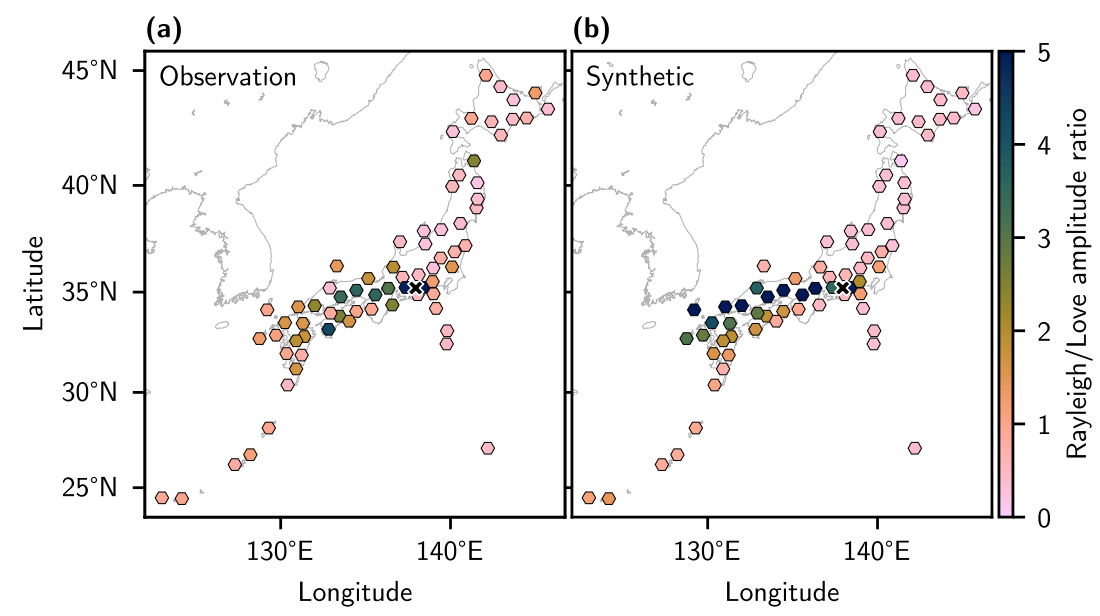

Figure 7. Comparison of the (a) observed and (b) synthetic Rayleigh- to Love-wave amplitude ratio for the F-net data. Each marker corresponds to a F-net station, colour coded by its Rayleigh- to Love-wave amplitude ratio. The cross marker shows the epicentre of the Tenryu landslide (E1). The synthetic Rayleigh- and Love-wave are computed from our preferred CSF model of the Tenryu landslide (E1). 
The two seismic events (E2 and E3) near Higashi-Matadani in Mie prefecture may relate to ones of the deep-seated landslides reported from field surveys after the typhoon transit. The E2 event is likely the Higashi-Matadani landslide, the largest field-reported landslide adjacent to the seismically determined location (Sakai 2011; Numamoto et al. 2012). Following a scaling relationship in Ekström and Stark (2013), we estimate the mass of the Higashi-Matadani event (E2) as $1.8 \times 10^{9} \mathrm{~kg}$ and the volume as $7.0 \times 10^{5} \mathrm{~m}^{3}$ from the resolved CSF model, assuming a density of $2.6 \times 10^{3} \mathrm{~kg} / \mathrm{m}^{3}$ (Yamada et al. 2013). The CSF model shows the mass displaced from south-east to north-west as a first order approximation of the mass movement. The model agrees well with the general changes of the topography, but cannot resolve the details, including possible redeposition that is modulated by the steep valley (Fig. 8). The third event (E3) occurred $~ 3.5 \mathrm{~min}$ before the Higashi-Matadani landslide (E2) (Figs. 4b, S3 and S4), but is challenging to locate with the current dataset. This event is likely the Mochiyama-Tanigawa landslide, which is located about $1 \mathrm{~km}$ north-west of Higashi-Matadani landslide (Sakai 2011; Numamoto et al. 2012). If so, the source area of this landslide is about $30 \%$ of the Higashi-Matadani landslide. However, the occurrence time of the Higashi-Matadani landslide is $40 \mathrm{~min}$ before our detection time as reported by local residents (Numamoto et al. 2012). The timing inconsistency undermines the landslide hypothesis. However, no coherent seismic phases can be identified from near-field records $40 \mathrm{~min}$ before our detection. Alternatively, the smaller signals may come from a precursory event of the Higashi-Matadani landslide. We examine the 3D particle motions of four nearsource stations. The analysis shows similarities between the particle motions of the events E2 and E3. However, this qualitative exercise cannot conclusively determine the relation between E2 and E3, largely because of the noisy horizontal F-net records. 

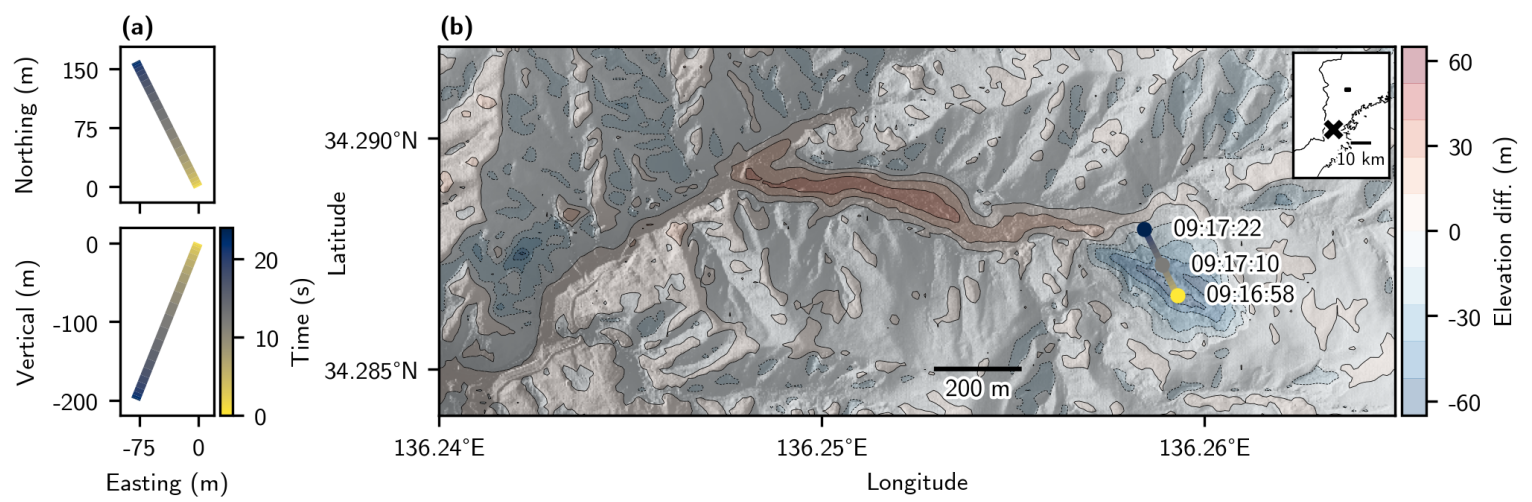

Figure 8. Mass trajectory for the Higashi-Matadani landslide (E2) and the topography change of the Higashi-Matadani landslide site. (a) East-North and East-Vertical trajectories (displacements) of the centre of mass. Colour represents the time. (b) Coloured contour denotes the differentiation of digital elevation models (DEMs) before and after the landslide. Background topography is the DEM after the landslide. Coloured line is the trajectory of the centre of mass, along with the time on September 4, 2011 (UTC). The inset is the regional map. The cross marker is the epicentre of the Higashi-Matadani landslide. The small rectangle is the area of Fig. $8 \mathrm{~b}$. The black line denotes the coastline and the administrative boundary. 


\subsection{Empirical scaling relationship of attributes of Tenryu landslide E1}

Our preferred CSF model of the Tenryu landslide $(\mathrm{E} 1)$ has a maximum centroid force $\left(F_{\max }\right)$ of $0.82 \times 10^{10} \mathrm{~N}$, suggesting a total displaced mass of $4.4 \times 10^{9} \mathrm{~kg}$ when assuming an empirical scaling relationship in Ekström and Stark (2013). To understand the landslide dynamics, we explore the CSF model uncertainties by examining an ensemble of models that can explain the observations within $5 \%$ of the minimum misfit $(\leq 0.296)$ (Table. 2, Fig. S7). This exercise suggests that the $F_{\max }$ is likely within $0.77 \pm 0.06 \times 10^{10} \mathrm{~N}$, indicating that the displaced mass ranges from $3.8-4.5 \times 10^{9} \mathrm{~kg}$. This seismically inferred total mass agrees with the field survey estimate, despite that the empirical scaling relationship was drawn from landslides ten times larger than the Tenryu event (Fig. 9a). For example, the Siachen landslides in the high mountains of Pakistani Kashmir deposited mass complexes on the order of $0.188 \times 10^{12} \mathrm{~kg}$ and generated centroid forces on the order of $10^{11} \mathrm{~N}$ (Ekström and Stark 2013). However, the total masses $(m)$ and the centroid peak forces of both the Siachen landslides and the Tenryu landslide follow the same scaling relationship, $m=0.54 F_{\max }$ (Ekström and Stark 2013) (Fig. 9a). Further, the maximum momentum from the CSF model and the $M_{\text {SW }}$ magnitude of the Tenryu landslide fit other scaling relationships proposed in Ekström and Stark (2013) as well (Fig. 9c). These agreements validate the scaling relationships over a large range of landslide sizes (Ekström and Stark 2013).

With the seismically estimated mass, we can further obtain the sliding acceleration history and the failure trajectory of the Tenryu landslide from the CSF model (Fig. 5d) (Allstadt 2013; Gualtieri and Ekström 2018), which agrees well with the field survey observations (Fig. $5 e)$. The results show promises of using seismic observations to obtain accurate landslide trajectories in remote regions where satellite images or field surveys may be limited. To understand the landslide movement, we also estimate the dynamic frictional coefficient $\mu$ with a total mass of $3.11 \times 10^{9} \mathrm{~kg}$ (Text S1; Brodsky et al. 2003; Yamada et al. 2013), which ranges from 0.23 to 0.46 (Fig. S8), concurring with $\mu$ of documented major landslides $(0.2 \leq \mu \leq 0.6$, e.g. Mt. St. Helens; Brodsky et al. 2003). The obtained frictional coefficient(s) is also proportional to the displaced volume $(V)$ as $\mu \sim V^{-0.0774}$, which scaling relationship suggests a possible velocity-weakening friction law that uniformly applies to small and large landslides (Lucas et al. 2014).

The potential energy loss $\Delta E$ of the Tenryu landslide do not scale with its runout duration $\Delta t$ (Fig. 9b) as $\Delta t \propto \Delta E^{\frac{1}{8}}$ proposed in Ekström and Stark (2013). This is likely because the vertical displacement is comparable to the runout length of the Tenryu landslide (Fig. $5 \mathrm{~d})$, in contrast to the landslides dominated by horizontal movements in other regions. The 

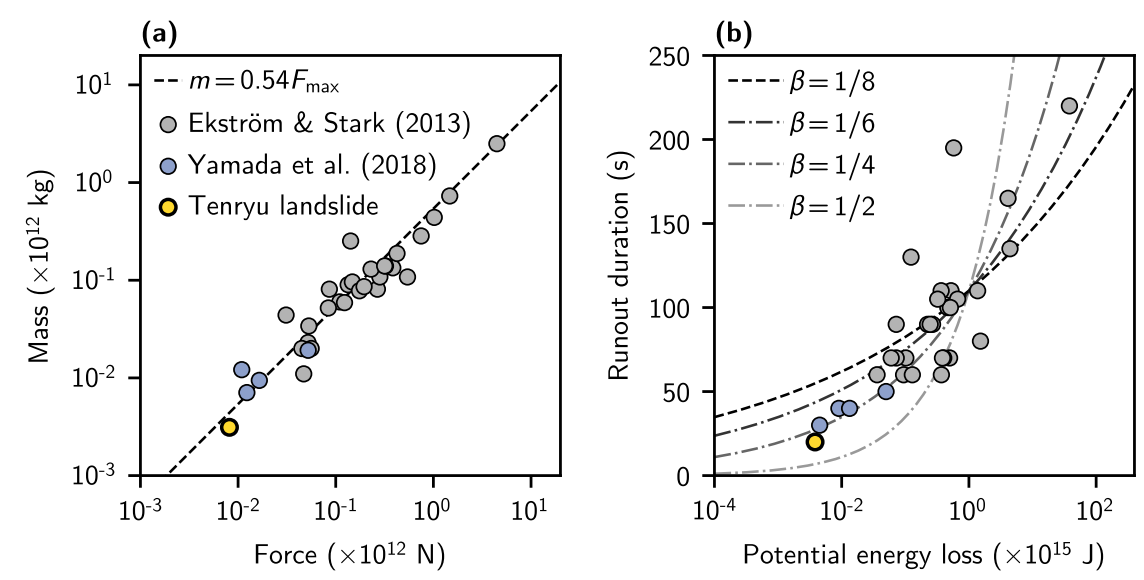

(c)
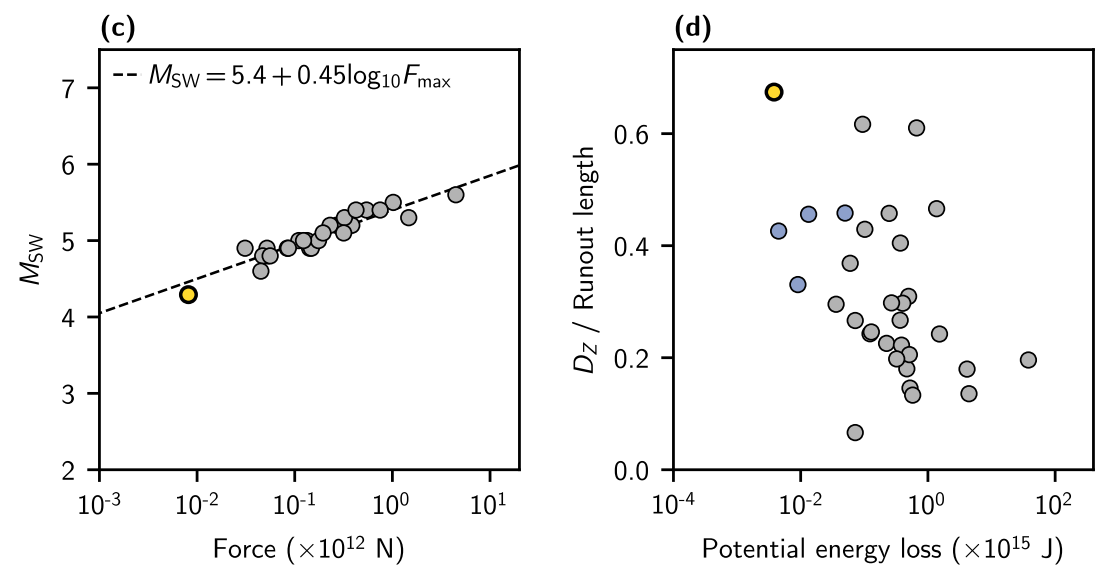

Figure 9. Scatter plot of landslide parameters. (a) Maximum centroid force $\left(F_{\max }\right)$ versus landslide mass. The Tenryu landslide mass in this study is from field observations. (b) Potential energy loss $\Delta E$ versus runout duration $\Delta t$. The curves plot $\Delta t=110 \Delta E^{\beta}$ (Ekström and Stark 2013, for $\beta=1 / 8$ ). (c) $F_{\max }$ versus surface wave magnitude $\left(M_{\mathrm{SW}}\right)$. (d) Potential energy loss versus the ratio of the vertical mass-centre displacement $\left(D_{Z}\right)$ and runout length. The runout length corresponds to the summation of the East-West, North-South, Up-Down displacement vectors from the CSF modelling.

Tenryu landslide occurred within a narrow valley and displaced along a steep slope, which is underlain by the alternated layers of sandstone and mudstone (Fig. 5e; Kanto Regional Forest Office Japan 2012; Yumoto and Takashima 2013). The layers are the Late Cretaceous accretionary-sedimentary rocks that develop fragile textures involving fractures and joints (Kanto Regional Forest Office Japan 2012). Similar geological predispositions of deep-seated landslides are also found in the southwest direction on the ridgeline of the landslide (Fig. $5 \mathrm{e})$. High erosion rate due to the extreme climate and active tectonic regime may have facilitated the development of high-relief mountains and steep hills across the Japanese island, which likely causes landslides in the region with short durations and large vertical displacements (Oguchi et al. 2001; Yamada et al. 2018). The observed differences between the Tenryu 
landslide and other catastrophic landslides support the hypothesis that the power-law co-

efficient (e.g., $\frac{1}{8}$ ) reflects the topographical variations, which has also been observed in the other field, laboratory, and analytic studies (Hibert et al. 2011; Levy et al. 2015; Farin et al. 2018).

\subsection{Outlook on real-time monitoring of landslides}

The Tenryu landslide is $\sim 400 \mathrm{~km}$ east from the track of Typhoon Talas in a region with intense precipitations from the typhoon (Fig. 1b). Investigating such hazards away from the track requires a robust detection method that can effectively monitor a broad region. Our results suggest a useful detection algorithm that can identify small ( $\sim 100 \mathrm{~m}$ scale) landslides with the existing F-net stations, and it is the first time the method being applied to detect and resolve previously unknown subaerial landslides in the region. Previous studies rely on a dense temporal network (Fan et al. 2020), and our results show promises to implement the technique to study environmental processes in regions with the existing permanent networks. Our approach is effective because it does not require phase-picking, prior knowledge of source types, or an accurate velocity model to calculate the travel times. Our approach uses local coherence across a triad, and stations of each triad would record waves travelling through a similar path. This helps to remove strong path effects of seismic wave propagation and hence is effective to detect remote landslides. Though requiring proper modifications of the method, our results suggest a future use of the Hi-net tiltmeter (e.g. Tonegawa et al. 2006) to systematically detect and locate landslides from 2004 to date. Such efforts will reveal the occurrence evolution and may aid deciphering the failure physics of the landslides in the region.

Although ground, aerial, and satellite methods can be used to map landslides with high spatial resolution, it is worth mentioning that it took 3 days for the local agencies to identify and survey the Tenryu landslide (Yumoto and Takashima 2013). These methods are often hampered by poor weather, restricting access and satellite visibility (e.g. Razak et al. 2013). In this study, we demonstrate that applying a suite of seismological analyses to regional seismic networks can effectively identify landslides from earthquakes and determine the dynamic processes of such failure events, including cross-examining sources resolved from our surface wave detector with standard catalogs, inspecting seismic wave signatures across multiple period bands, and modelling the failure histories as centroid single forces. Future combination of Hi-net $(>1 \mathrm{~Hz}$ ) and F-net (20 to $50 \mathrm{~s}$ ) observations may provide an efficient way to screen our detected seismic sources as the frequency dependent radiation may be di- 
agnostic to identify landslides. In conjunction with automatic classification algorithms (e.g. Manconi et al. 2016; Dammeier et al. 2016), our results show the possibility of using seismic records to resolve landslide locations and times in near-real time. Such data products can serve as preliminary results to assist future risk management and to guide rapid response of post-event surveys.

\section{CONCLUSIONS}

We detect and locate multiple landslides by applying the AELUMA method to 20-to-50-s period surface waves that were recorded by multiple spatially disconnected seismic arrays near Japan. These landslides occurred during the passage of Typhoon Talas 2011, including the Tenryu landslide (E1), the Higashi-Matadani landslide (E2), and the Mochiyama-Tanigawa landslide (E3). The Tenryu landslide displaced 1.2-1.5 $\times 10^{6} \mathrm{~m}^{3}$ sediment and rock, and generated coherent intermediate-period Rayleigh waves that propagated up to $3000 \mathrm{~km}$ epicentral distance. Such signals are distinctly different from those of regular earthquakes. Our observations also show that landslide attributes, including the mass, inertial force, and surface magnitude, empirically scale with each other, and these scaling relationships are likely invariant for landslides of different sizes. Therefore, our methods are useful to identify small landslides and infer their physical attributes for regions with only sparse seismic networks. Our approach requires minimum assumptions and has potential to be implemented in nearreal time for monitoring landslide activity and assisting future risk assessment.

\section{ACKNOWLEDGMENTS}

The authors thank NIED and IRIS for making the data publicly available. The facilities of IRIS Data Services, and specifically the IRIS Data Management Center, were used for access to waveforms, related metadata, and/or derived products used in this study. IRIS Data Services are funded through the Seismological Facilities for the Advancement of Geoscience (SAGE) Award of the National Science Foundation under Cooperative Support Agreement EAR-1851048. This work has been supported by Grant-in-Aid for JSPS Fellows JP19J00814 (R.O.) and JSPS Grant-in-Aid for Early-Career Scientists JP17H04733 (M.Y.) and JP20K14570 (R.O.). The authors would like to acknowledge the editor Eiichi Fukuyama, the assistant editor Louise Alexander, the two anonymous reviewers, Goran Ekström and Velio Coviello for their constructive suggestions, which have led to improvements of the paper. The authors 
thank Haoran Meng, Xinyu Luo, Taka'aki Taira, Shunsuke Takemura, and Takahiko Uchide for fruitful discussion.

\section{DATA AVAILABILITY}

Waveform data at F-net (https://doi.org/10.17598/nied.0005) and Hi-net (https://doi .org/ 10.17598/nied.0003) are available through NIED website (https://www.hinet.bosai.go.jp/ ?LANG=en). The facilities of IRIS Data Services and specifically the IRIS DMC (https://ds. iris.edu/ds/nodes/dmc/) are used for access to waveforms and related metadata. AELUMA MATLAB code bundle is available from IRIS DMC (https://ds.iris.edu/ds/products/ infrasound-aeluma/). Green's functions used for the CSF modelling are provided by IRIS DMC Data Services Products: Synthetics Engine (https://doi.org/10.17611/DP/SYNGINE.1). The typhoon tracks are downloaded at https://www.jma.go.jp/jma/jma-eng/jma-center/ rsmc-hp-pub-eg/RSMC_HP.htm. The AMeDAS precipitation data are downloaded at https: //www. data.jma.go.jp/gmd/risk/obsdl/index. php (only in Japanese). The DEM data are available at https://fgd.gsi.go.jp/download/menu. php (only in Japanese). ObsPy (Beyreuther et al. 2010, version 1.1.0; https://doi.org/10.5281/zenodo.165135), matplotlib (Hunter 2007, version 3.0.3; https://doi.org/10.5281/zenodo.2577644), and the Generic Mapping Tools (Wessel and Luis 2017, version 6.1; http://doi.org/10.5281/zenodo.3924517) were used to generate figures. The CVX package (Grant and Boyd 2008, 2014, http://cvxr.com/cvx) was used for solving the least-square problem in locating source. The DEM data after the Tenryu landslide was provided by Chubu Regional Development Bureau, Ministry of Land, Infrastructure, Transport and Tourism, Japan. The DEM data of the Higashi-Matadani landslide was provided by the Geospatial Information Authority of Japan. 


\section{REFERENCES}

Allstadt, K., 2013. Extracting source characteristics and dynamics of the August 2010 Mount Meager landslide from broadband seismograms, J. Geophys. Res. Earth Surf., 118(3), 1472-1490, doi: 10.1002/jgrf.20110.

Beyreuther, M., Barsch, R., Krischer, L., Megies, T., Behr, Y., and Wassermann, J., 2010. ObsPy: A Python Toolbox for Seismology, Seismol. Res. Lett., 81(3), 530-533, doi : 10.1785/gssrl.81 .3.530.

Brodsky, E. E., Gordeev, E., and Kanamori, H., 2003. Landslide basal friction as measured by seismic waves, Geophys. Res. Lett., 30(24), 1-5, doi :10.1029/2003GL018485.

Chao, W.-A., Wu, Y.-M., Zhao, L., Chen, H., Chen, Y.-G., Chang, J.-M., and Lin, C.-M., 2017. A first near real-time seismology-based landquake monitoring system, Sci. Rep., 7(1), 43510, doi : 10.1038/srep43510.

Chigira, M., Tsou, C.-Y., Matsushi, Y., Hiraishi, N., and Matsuzawa, M., 2013. Topographic precursors and geological structures of deep-seated catastrophic landslides caused by Typhoon Talas, Geomorphology, 201, 479-493, doi:10.1016/j.geomorph.2013.07.020.

Dalton, C. A. and Ekström, G., 2006. Global models of surface wave attenuation, J. Geophys. Res. Solid Earth, 111(B5), n/a-n/a, doi : 10.1029/2005JB003997.

Dammeier, F., Moore, J. R., Hammer, C., Haslinger, F., and Loew, S., 2016. Automatic detection of alpine rockslides in continuous seismic data using hidden Markov models, J. Geophys. Res. Earth Surf., 121(2), 351-371, doi : 10.1002/2015JF003647.

de Groot-Hedlin, C. D. and Hedlin, M. A., 2015. A method for detecting and locating geophysical events using groups of arrays, Geophys. J. Int., 203(2), 960-971, doi :10.1093/gji/ggv345.

de Groot-Hedlin, C. D. and Hedlin, M. A. H., 2018. A New Automated Approach to Detecting and Locating Seismic Events Using Data from a Large Network, Bull. Seismol. Soc. Am., 108(4), 2032 2045, doi : 10.1785/0120180072.

Dietze, M., Mohadjer, S., Turowski, J. M., Ehlers, T. A., and Hovius, N., 2017. Seismic monitoring of small alpine rockfalls - validity, precision and limitations, Earth Surf. Dyn., 5(4), 653-668, doi : 10.5194/esurf-5-653-2017.

Doi, I. and Maeda, T., 2020. Landslide Characteristics Revealed by High-Frequency Seismic Waves from the 2017 Landslide in Central Japan, Seismol. Res. Lett., doi : 10.1785/0220200032.

Dziewonski, A. M. and Anderson, D. L., 1981. Preliminary reference Earth model, Phys. Earth Planet. Inter., 25(4), 297-356, doi :10.1016/0031-9201(81)90046-7.

Dziewonski, A. M., Chou, T.-A., and Woodhouse, J. H., 1981. Determination of earthquake source parameters from waveform data for studies of global and regional seismicity, J. Geophys. Res. Solid Earth, 86(B4), 2825-2852, doi :10.1029/JB086iB04p02825.

Ekström, G., 2006. Global Detection and Location of Seismic Sources by Using Surface Waves, Bull. Seismol. Soc. Am., 96(4A), 1201-1212, doi :10.1785/0120050175.

Ekström, G. and Stark, C. P., 2013. Simple Scaling of Catastrophic Landslide Dynamics, Science, 
339(6126), 1416-1419, doi:10.1126/science. 1232887.

Ekström, G., Nettles, M., and Dziewoński, A., 2012. The global CMT project 2004-2010: Centroid-moment tensors for 13,017 earthquakes, Phys. Earth Planet. Inter., 200-201, 1-9, doi:10.1016/j.pepi.2012.04.002.

Fan, W., de Groot-Hedlin, C. D., Hedlin, M. A. H., and Ma, Z., 2018. Using surface waves recorded by a large mesh of three-element arrays to detect and locate disparate seismic sources, Geophys. J. Int., 215(2), 942-958, doi : 10.1093/gji/ggy316.

Fan, W., McGuire, J. J., Groot-Hedlin, C. D., Hedlin, M. A. H., Coats, S., and Fiedler, J. W., 2019. Stormquakes, Geophys. Res. Lett., 46(22), 12909-12918, doi : 10.1029/2019GL084217.

Fan, W., McGuire, J. J., and Shearer, P. M., 2020. Abundant Spontaneous and Dynamically Triggered Submarine Landslides in the Gulf of Mexico, Geophys. Res. Lett., 47(12), 1-16, doi : 10.1029/2020GL087213.

Farin, M., Mangeney, A., de Rosny, J., Toussaint, R., and Trinh, P.-T., 2018. Link Between the Dynamics of Granular Flows and the Generated Seismic Signal: Insights From Laboratory Experiments, J. Geophys. Res. Earth Surf., 123(6), 1407-1429, doi :10.1029/2017JF004296.

Fuchs, F., Lenhardt, W., and Bokelmann, G., 2018. Seismic detection of rockslides at regional scale: examples from the Eastern Alps and feasibility of kurtosis-based event location, Earth Surf. Dyn., 6(4), 955-970, doi : 10.5194/esurf-6-955-2018.

GEBCO Bathymetric Compilation Group 2019, 2019. The GEBCO_2019 Grid - a continuous terrain model of the global oceans and land, doi:10/c33m.

Geospatial Information Authority of Japan, 2011. Aerial photos of the Tenryu landslide, Retrieved from: https://saigai.gsi.go.jp/2011typhoon12/html/112.html.

Grant, M. and Boyd, S., 2008. Graph implementations for nonsmooth convex programs, in Recent $A d v$. Learn. Control, Lecture Notes in Control and Information Sciences, pp. 95-110, eds Blondel, V., Boyd, S., and Kimura, H., Springer-Verlag Limited, Retrieved from: http: //cvxr. com/cvx/.

Grant, M. and Boyd, S., 2014. CVX: Matlab Software for Disciplined Convex Programming, version 2.1, Retrieved from: http://cvxr.com/cvx/.

Gualtieri, L. and Ekström, G., 2018. Broad-band seismic analysis and modeling of the 2015 Taan Fjord, Alaska landslide using Instaseis, Geophys. J. Int., 213(3), 1912-1923, doi : 10.1093/gji/ggy086.

Hewitt, K., Clague, J. J., and Orwin, J. F., 2008. Legacies of catastrophic rock slope failures in mountain landscapes, Earth-Science Rev., 87(1-2), 1-38, doi :10.1016/j.earscirev.2007.10.002.

Hibert, C., Mangeney, A., Grandjean, G., and Shapiro, N. M., 2011. Slope instabilities in Dolomieu crater, Réunion Island: From seismic signals to rockfall characteristics, J. Geophys. Res., 116(F4), F04032, doi : 10.1029/2011JF002038.

Hibert, C., Stark, C. P., and Ekström, G., 2015. Dynamics of the Oso-Steelhead landslide from broadband seismic analysis, Nat. Hazards Earth Syst. Sci., 15(6), 1265-1273, 
doi : 10.5194/nhess-15-1265-2015.

Hibert, C., Provost, F., Malet, J.-P., Maggi, A., Stumpf, A., and Ferrazzini, V., 2017. Automatic identification of rockfalls and volcano-tectonic earthquakes at the Piton de la Fournaise volcano using a Random Forest algorithm, J. Volcanol. Geotherm. Res., 340, 130-142, doi :10.1016/j.jvolgeores.2017.04.015.

Hibert, C., Michéa, D., Provost, F., Malet, J.-P., and Geertsema, M., 2019. Exploration of continuous seismic recordings with a machine learning approach to document $20 \mathrm{yr}$ of landslide activity in Alaska, Geophys. J. Int., 219(2), 1138-1147, doi:10.1093/gji/ggz354.

Hunter, J. D., 2007. Matplotlib: A 2D Graphics Environment, Comput. Sci. Eng., 9(3), 90-95, doi : 10.1109/MCSE. 2007.55.

IES, 1996. Broadband Array in Taiwan for Seismology, doi :10.7914/SN/TW.

Japan Meteorological Agency, 2011. The Seismological Bulletin of Japan, Retrieved from: https: //www.data.jma.go.jp/svd/eqev/data/bulletin/index_e.html.

Kanamori, H. and Given, J. W., 1982. Analysis of long-period seismic waves excited by the May 18, 1980, eruption of Mount St. Helens-A terrestrial monopole?, J. Geophys. Res. Solid Earth, 87(B7), 5422-5432, doi:10.1029/JB087iB07p05422.

Kanto Regional Forest Office Japan, 2012. Report: Disaster investigation of the 2011 Misakubo landslide, Tech. rep.

Kawakatsu, H., 1989. Centroid single force inversion of seismic waves generated by landslides, $J$. Geophys. Res., 94(B9), 12363, doi : 10.1029/JB094iB09p12363.

Kennett, B. L. N. and Engdahl, E. R., 1991. Traveltimes for global earthquake location and phase identification, Geophys. J. Int., 105(2), 429-465, doi:10.1111/j.1365-246X.1991 .tb06724.x.

Krischer, L., Hutko, A. R., van Driel, M., Stähler, S., Bahavar, M., Trabant, C., and Nissen-Meyer, T., 2017. On-Demand Custom Broadband Synthetic Seismograms, Seismol. Res. Lett., 88(4), 11271140, doi: $10.1785 / 0220160210$.

Lee, D. T. and Schachter, B. J., 1980. Two algorithms for constructing a Delaunay triangulation, Int. J. Comput. Inf. Sci., 9(3), 219-242, doi : 10.1007/BF00977785.

Levy, C., Mangeney, A., Bonilla, F., Hibert, C., Calder, E. S., and Smith, P. J., 2015. Friction weakening in granular flows deduced from seismic records at the Soufrière Hills Volcano, Montserrat, J. Geophys. Res. Solid Earth, 120(11), 7536-7557, doi:10.1002/2015JB012151.

Li, W., Chen, Y., Liu, F., Yang, H., Liu, J., and Fu, B., 2019. Chain-Style Landslide Hazardous Process: Constraints From Seismic Signals Analysis of the 2017 Xinmo Landslide, SW China, J. Geophys. Res. Solid Earth, 124(2), 2025-2037, doi : 10.1029/2018JB016433.

Lin, C. H., Kumagai, H., Ando, M., and Shin, T. C., 2010. Detection of landslides and submarine slumps using broadband seismic networks, Geophys. Res. Lett., 37(22), n/a-n/a, doi : 10.1029/2010GL044685.

Lucas, A., Mangeney, A., and Ampuero, J. P., 2014. Frictional velocity-weakening in landslides on 
Earth and on other planetary bodies, Nat. Commun., 5(1), 3417, doi:10.1038/ncomms4417.

Manconi, A., Picozzi, M., Coviello, V., De Santis, F., and Elia, L., 2016. Real-time detection, location, and characterization of rockslides using broadband regional seismic networks, Geophys. Res. Lett., 43(13), 6960-6967, doi : 10.1002/2016GL069572.

Moretti, L., Mangeney, A., Capdeville, Y., Stutzmann, E., Huggel, C., Schneider, D., and Bouchut, F., 2012. Numerical modeling of the Mount Steller landslide flow history and of the generated long period seismic waves, Geophys. Res. Lett., 39(16), L16402, doi : 10.1029/2012GL052511.

Moretti, L., Mangeney, A., Walter, F., Capdeville, Y., Bodin, T., Stutzmann, E., and Le Friant, A., 2020. Constraining landslide characteristics with Bayesian inversion of field and seismic data, Geophys. J. Int., 221(2), 1341-1348, doi:10.1093/gji/ggaa056.

NIED, 2019. NIED F-net, doi :10.17598/nied.0005.

Nissen-Meyer, T., van Driel, M., Stähler, S. C., Hosseini, K., Hempel, S., Auer, L., Colombi, A., and Fournier, A., 2014. AxiSEM: broadband 3-D seismic wavefields in axisymmetric media, Solid Earth, 5(1), 425-445, doi : 10.5194/se-5-425-2014.

Numamoto, S., Takezawa, N., Ito, H., Matsuoka, A., and Hayashi, S., 2012. Deep-seated collapses and sediment transport caused by Typhoon No. 12 at Odaicho in Mie Prefecture in 2011, in Abstr. Annu. Conf. Japan Soc. Eros. Control Eng., Retrieved from: http://www. jsece.or.jp/event/conf/abstract/ 2012/pdf/Pb-33.pdf.

Oguchi, T., Saito, K., Kadomura, H., and Grossman, M., 2001. Fluvial geomorphology and paleohydrology in Japan, Geomorphology, 39(1-2), 3-19, doi:10.1016/S0169-555X(01)00048-4.

Provost, F., Hibert, C., and Malet, J.-P., 2017. Automatic classification of endogenous landslide seismicity using the Random Forest supervised classifier, Geophys. Res. Lett., 44(1), 113-120, doi:10.1002/2016GL070709.

Razak, K. A., Santangelo, M., Van Westen, C. J., Straatsma, M. W., and de Jong, S. M., 2013. Generating an optimal DTM from airborne laser scanning data for landslide mapping in a tropical forest environment, Geomorphology, 190, 112-125, doi : 10.1016/j.geomorph.2013.02.021.

Sakai, T., 2011. Report on the Joint Field Survey of Disasters in Mie Prefecture Caused by Typhoon No. 12 in 2011 by Japanese Geotechnical Society and Chubu Geological Survey Association, Tech. rep., Retrieved from: https://www.jiban.or.jp/file/file/mie1006.pdf.

Seo, N., Tsuchiya, S., Osaka, O., Takashima, M., and Asami, K., 2012. Large-scale collapse and landslide dam in a national forest in Mizukubo Town, Hamamatsu City, due to heavy rains by Typhoon No.12 (2011), in Abstr. Annu. Conf. Japan Soc. Eros. Control Eng., Retrieved from: http: //www.jsece.or.jp/event/conf/abstract/2012/pdf/T1-04.pdf.

Spiker, E. C. and Gori, P. L., 2003. National landslide hazards mitigation strategy : a framework for loss reduction, Tech. rep., doi:10.3133/cir1244.

Thompson, C. M. and Shure, L., 2016. Image Processing Toolbox: For Use with MATLAB;[user's Guide], MathWorks. 
Tonegawa, T., Hirahara, K., Shibutani, T., and Shiomi, K., 2006. Upper mantle imaging beneath the Japan Islands by Hi-net tiltmeter recordings, Earth, Planets Sp., 58(8), 1007-1012, doi : 10.1186/BF03352605.

Tsai, V. C. and Ekström, G., 2007. Analysis of glacial earthquakes, J. Geophys. Res., 112(F3), F03S22, doi : 10.1029/2006JF000596.

U.S. Geological Survey Earthquake Hazards Program, 2017. Advanced National Seismic System (ANSS) Comprehensive Catalog of Earthquake Events and Products, doi : 10.5066/F7MS3QZH.

van Driel, M., Krischer, L., Stähler, S. C., Hosseini, K., and Nissen-Meyer, T., 2015. Instaseis: instant global seismograms based on a broadband waveform database, Solid Earth, 6(2), 701-717, doi : 10.5194/se-6-701-2015.

Wessel, P. and Luis, J. F., 2017. The GMT/MATLAB Toolbox, Geochemistry, Geophys. Geosystems, 18(2), 811-823, doi:10.1002/2016GC006723.

Yamada, M., Matsushi, Y., Chigira, M., and Mori, J., 2012. Seismic recordings of landslides caused by Typhoon Talas (2011), Japan, Geophys. Res. Lett., 39(13), 1-5, doi : 10. 1029/2012GL052174.

Yamada, M., Kumagai, H., Matsushi, Y., and Matsuzawa, T., 2013. Dynamic landslide processes revealed by broadband seismic records, Geophys. Res. Lett., 40(12), 2998-3002, doi:10.1002/grl. 50437.

Yamada, M., Mangeney, A., Matsushi, Y., and Matsuzawa, T., 2018. Estimation of dynamic friction and movement history of large landslides, Landslides, 15(10), 1963-1974, doi : 10.1007/s10346-018-1002-4.

Yumoto, H. and Takashima, M., 2013. Investigation and analysis of the landslide dam in Mizukubo town, in Publ. Collect. For. For. Technol. Kanto Reg. For. Off., pp. 69-73, Retrieved from: https:// jglobal . jst. go.jp/en/detail?JGLOBAL_ID=201302252352901877\&rel=0.

Zhang, Z., He, S., Liu, W., Liang, H., Yan, S., Deng, Y., Bai, X., and Chen, Z., 2019. Source characteristics and dynamics of the October 2018 Baige landslide revealed by broadband seismograms, Landslides, 16(4), 777-785, doi :10.1007/s10346-019-01145-3. 